\title{
El desarrollo del régimen jurídico de la nulidad de derecho público
}

\author{
Ricardo Concha Machuca*
}

\section{RESUMEN}

A base de dos diversos modelos normativos de nulidad, este trabajo apunta a determinar que la nulidad de derecho público construida en Chile a base constitucional carece de una regulación exhaustiva. En consecuencia, se requiere que se establezcan dichos elementos.

$$
\text { Nulidad - derecho público - régimen jurídico }
$$

\section{The development of public law annulment}

\begin{abstract}
This paper intends to prove that Chile's public law annulment has been developed without a suitable legal framework. To do so, this work will analyse two legislative models and will give suggestions on how to improve the current legislation.
\end{abstract}

Annulment - public law - legal framework

* Abogado, Doctor en Derecho, Profesor de Derecho Civil en la Universidad de Talca, Chile. Correo electrónico: rconcha@utalca.cl

Artículo recibido el 30 de marzo de 2013 y aceptado para su publicación por el Comité Editorial el 28 de octubre de 2013. 


\section{INTRODUCCIÓN}

$\mathrm{E}$ ste trabajo apunta a determinar si la dogmática chilena, y en cierta medida la jurisprudencia, han logrado delinear un régimen jurídico exhaustivo para la nulidad de derecho público. El problema parte de la base de que, como se sabe, en el derecho chileno no se ha establecido a nivel legislativo una reglamentación acabada para nulidad de derecho público. Para ello se argumenta de la siguiente manera: en la primera parte se consideran las cuestiones o materias que los regímenes jurídicos de nulidad que se han tomado como modelo han regulado. A este respecto no necesariamente interesa el cómo se ha regulado, sino el qué se ha regulado. Se consideran como parámetros los aspectos que se regulan en la nulidad pública en un ordenamiento del régimen europeo continental de raíz latina, específicamente en el derecho español, por tratarse de un derecho administrativo preferentemente legislado. Dentro del derecho chileno se consideran los aspectos que ha regulado el Código Civil (1857), ya que dicho cuerpo normativo contiene un régimen típico de nulidad. En la segunda parte se examina si la dogmática de la nulidad de derecho público, en tanto nulidad administrativa, ha logrado establecer un régimen jurídico que cumpla con esos parámetros.

El propósito de este trabajo no consiste en proponer importar la solución de alguno de los modelos indicados, sino que demostrar los elementos que se requieren para configurar un régimen exhaustivo de nulidad.

\section{MODELO DE RÉGIMEN JURÍDICO}

La nulidad, entendida como el mecanismo establecido por el ordenamiento jurídico para depurarse de normas o actos inválidos ${ }^{1}$, goza de un distinto grado de desarrollo de su régimen jurídico según el campo del derecho de que se trate, o según los diversos derechos nacionales.

En el marco del derecho europeo continental se encuentran regímenes de nulidad en el campo del derecho público. No ocurre lo mismo en el campo del derecho público chileno. En el derecho chileno es en el campo del derecho privado donde se encuentra establecido en el Código Civil (1857) un acabado y completo régimen de nulidad diseñado preferentemente para las convenciones. De lo establecido en dichas regulaciones es posible inducir los elementos que una reglamentación de la nulidad debe contemplar para considerarse un régimen jurídico exhaustivo, independientemente de cómo se regule cada uno de esos aspectos.

${ }^{1}$ En este sentido Pérez, J.L., "Validez, aplicabilidad y nulidad. Un análisis comparativo de la teoría del derecho y la dogmática jurídica", en Doxa, núm. 22, 1999, p. 264, señala que "la institución de la nulidad tiene como finalidad depurar el ordenamiento jurídico del conjunto de normas que han sido creadas irregularmente". Sobre la concepción sustancial de la nulidad, entendida como la desaparición de los efectos del acto en la medida de la no observancia de la ley, Thibierge, C., Nulidad, restituciones y responsabilidad (traducc. Gustavo de Greiff), Ed. Universidad Externado de Colombia, Bogotá, 2010, pp. 339-360. 
Para los efectos de este trabajo, los modelos se toman con reserva, únicamente en cuanto a cuáles son los aspectos que se regulan, mas no el contenido preciso de la reglamentación, el que obedece a circunstancias específicas de cada modelo en concreto.

\section{El modelo comparado de nulidad en el ámbito público}

En el marco de los derechos europeos continentales de raíz latina que establecen regímenes típicos de nulidad es usual distinguir entre nulidad absoluta y anulabilidad. A la nulidad absoluta también se la denomina como nulidad de pleno derecho.

Respecto de la nulidad de pleno derecho Santamaría Pastor demostró que el origen de la doctrina de la nulidad ipso iure se debe a una interpretación errada de las fuentes históricas romanas, específicamente en lo que se refiere al procedimiento romano. Explica que el Pretor denegaba la acción cuando el acto presentaba un vicio de nulidad, todo ello previo a que el Juez conociera del asunto. De este modo, concurría un pronunciamiento previo de la autoridad, por lo que no era necesario que el Juez declarara la nulidad (lo que claramente no implica que la nulidad operara de pleno derecho). E indica que, como en todas las épocas, en el ordenamiento romano no existieron nulidades de pleno derecho ${ }^{2}$.

Sin perjuicio de ello, en el caso español, como regímenes típicos de nulidad se contempla expresamente la distinción entre nulidad de pleno derecho y la anulabilidad, cada una con su respectivo régimen jurídico establecido a nivel legislativo. Tomás-Ramón Fernández luego de analizar la teoría de la nulidad administrativa sostiene que el análisis de la teoría de las nulidades en el derecho administrativo le ha permitido poner de relieve en qué medida los principios inspiradores de esta específica rama del derecho inciden sobre el esquema dogmático de la teoría general del derecho, y concretamente señala que le ha permitido comprobar que dicho esquema dogmático no se altera esencialmente por el juego de aquellos principios en lo que a las distintas categorías de invalidez de los actos jurídicos se refiere, y señala que así los caracteres esenciales y definidores de la nulidad absoluta, y de la nulidad relativa ${ }^{3}$, permanecen sin variación en el derecho administrativo, tal y como han sido elaborados en el derecho común ${ }^{4}$.

De modo que, en el modelo señalado, la regulación pública sigue la estructura de la regulación privada, en cuanto a establecer regímenes típicos de nulidad de pleno derecho y anulabilidad 5 .

El régimen jurídico de la nulidad de pleno derecho establece:

${ }^{2}$ Santamaría, J., La nulidad de pleno derecho de los actos administrativos. Contribución a una teoría de la ineficacia en el derecho público, Instituto de Estudios Administrativos, Madrid, 1976, pp. 71-152.

${ }^{3}$ Lo que este autor denomina nulidad absoluta y nulidad relativa se denominan generalmente en dicho marco como nulidad de pleno derecho y anulabilidad (categorías que no son equivalentes a la nulidad absoluta y nulidad relativa según el Código Civil chileno).

${ }^{4}$ Fernández, T-R., La nulidad de los actos administrativos, Editorial Jurídica Venezolana, Caracas, 1979, p. 113.

5 En el mismo sentido Cano, T., "La invalidez de los actos administrativos y sus consecuencias", en Revista General de Derecho Administrativo, núm. 8, 2005, p. 40. 
(1) Causales tasadas, precisamente vicios que el legislador considera de mayor gravedad que los vicios que dan lugar a anulabilidad ${ }^{6}$; (2) se reglamenta la legitimidad activa de la acción de nulidad ${ }^{7}$; (3) imprescriptibilidad del vicio de nulidad, lo que comprende tanto la acción de nulidad como la revisión por parte de la propia Administración ${ }^{8}$; (4) los vicios de orden público pueden ser declarados de oficio9; (5) los vicios de nulidad de pleno derecho son insaneables, esto es, no procede la convalidación ${ }^{10}$; (6) en cuanto a los efectos: está dotada de efecto retroactivo, esto es ex tunc ${ }^{11}$, y (7) consta de un régimen de suspensión de la ejecución del acto viciado de nulidad ${ }^{12}$.

Por su parte el régimen jurídico de la anulabilidad establece:

(1) Una causal general de anulación frente a cualquier infracción del ordenamiento jurídico ${ }^{13}$; (2) debe ser alegada. Cuando lo es por la propia Administración, previamente

${ }^{6}$ Ibíd., p. 42 señala que "La diferencia de régimen jurídico entre la nulidad de pleno derecho y anulabilidad de los actos administrativos halla su justificación o fundamento en la distinta gravedad de los vicios que el legislador aprecia en uno y otro caso. Esa distinta gravedad de los vicios depende, a su vez, de los intereses que protegen las normas o principios violados por la Administración cuando dicta un acto nulo o anulable".

${ }^{7}$ Se reglamenta la posibilidad de pedir ante la propia Administración la declaración de nulidad. Se otorga a los particulares afectados (interesados) la posibilidad de exigir en cualquier tiempo a la Administración la declaración de nulidad de los actos administrativos. Ibíd., p. 43.

${ }^{8}$ Cano señala que dicha prescriptibilidad "ha de ser relativizada, pues, en rigor, ni la acción de nulidad ni la revisión de oficio por parte de la Administración es imprescriptible. El artículo 106 LAP establece [...], una serie de límites materiales a las facultades de revisión, límites que tratan de tutelar determinados principios (protección de la confianza, equidad, etc.) que se considera deben prevalecer sobre las consecuencias de la invalidez, y ello tanto si el acto es nulo como si es anulable”. Ibíd., p. 44. Cabe hacer presente que entre nosotros el tópico de la invalidación administrativa se refiere a un problema que ha tenido un desarrollo dogmático en gran medida separado del de la nulidad de derecho público, sobre dicha materia cfr. Millar, J., La potestad invalidatoria en el derecho chileno s/e, tesis de doctorado, Universidad de Chile, 2008, passim.

9 Aunque se refiere a la posibilidad de que la Administración declare la nulidad ex officio. Cano, T., "La invalidez de los actos administrativos y sus consecuencias", cit., p. 43. Tópico que en el derecho chileno ha tenido un desarrollo dogmático conocido como invalidación administrativa, en gran medida separado de la nulidad, cfr. Millar, J., La potestad invalidatoria en el derecho chileno, cit., passim.

${ }^{10}$ Esto pues solo se "permite la convalidación de los actos anulables mediante su subsanación, de modo que, al no ser posible la subsanación de los actos nulos de pleno derecho estos no podrían ser convalidados". Cano, T., "La invalidez de los actos administrativos y sus consecuencias", cit., p. 40.

${ }^{11}$ Ibíd., p. 48. "Las consecuencias de la nulidad de pleno derecho (la tradicional, pero errónea, eliminación del acto o su ineficacia) se producirían desde el momento en que este se dictó”.

12 Aunque Cano indica que "es más fácil [según la normativa] conseguir la suspensión en caso de nulidad de pleno derecho, pues uno de los criterios o circunstancias que el órgano administrativo ha de tener en cuenta para acordar la suspensión de la ejecución de un acto impugnado en vía de recurso es que dicha impugnación se fundamente en que el acto incurre en nulidad de pleno derecho. Se trata de obstaculizar la materialización de los efectos de los actos nulos de pleno derecho, dada la gravedad de los vicios en que los mismos incurren y, por tanto, de los bienes e intereses que se ven vulnerados. En la práctica, sin embargo, la invocación de la nulidad como causa de la suspensión no parece que sea muy atendida”. Ibíd., pp. 44-45.

${ }^{13}$ Beladíez, M., "La nulidad y la anulabilidad. Su alcance y significación”, en Revista de Administración Pública, núm. 133, 1994, pp. 164 y sgts. 
se debe declarar la lesividad del acto ${ }^{14}$; (3) se establece expresamente la prescriptibilidad del vicio ${ }^{15}$; (4) en cuanto a los efectos: está dotada únicamente de efecto hacia lo futuro, desde que se declara, esto es ex nunc ${ }^{16}$; (5) los vicios de anulabilidad son saneables, es decir, que procede la convalidación ${ }^{17}$; (6) además se contempla una regla que podría entenderse inspirada en el principio del nemo auditur ${ }^{18}$.

Ahora bien, cabe precisar que si bien existe un régimen típico de nulidad (nulidad de pleno derecho y anulabilidad), se ha estado lejos de constituir un régimen óptimo, pues algunos autores sostienen que dogmáticamente no se ha alcanzado una configuración técnica adecuada al efectivo funcionamiento de la nulidad en la realidad jurídica ${ }^{19}$.

\section{Régimen típico de nulidad en el Código Civil chileno}

La nulidad civil se encuentra diseñada para impugnar la validez de actos de derecho privado que implican el ejercicio de la autonomía contractual, actos que organizan el aspecto jurídico de intercambios espontáneos ${ }^{20}$. Por ello, dentro de la sistemática del Código Civil de Chile (1857) la nulidad se considera como un modo de extinguir las obligaciones. En este sentido, Domínguez indica que las reglas civiles de nulidad corresponden a los negocios patrimoniales de derecho privado en general, y en especial para los contratos 21 .

El régimen jurídico de la nulidad de derecho privado se halla en el título XX del libro IV, artículos 1681 a 1697 del Código Civil, con sus complementos que se hallan

${ }^{14}$ Cano, T., "La invalidez de los actos administrativos y sus consecuencias", cit., p. 43. Recientemente en un sentido diverso, los tribunales chilenos han reconocido la expresión lesividad, Corte Suprema, rol núm. 9352-2009, 28 de mayo de 2012.

15 Ibid., p. 44.

${ }^{16}$ Aunque esta característica es cuestionada: "si el acto es solo anulable (regla general en el Derecho administrativo) dichas consecuencias solo se producirían desde el momento en que se aprecia y declara el vicio del acto. Recientemente se ha sostenido, sin embargo, que en el caso de la anulabilidad debe distinguirse entre actos cuya eficacia se agota en una sola aplicación (pago de una multa), en cuyo caso la eficacia de la anulabilidad será ex tunc (la cuantía de la multa debe ser devuelta), y actos cuya eficacia se extiende en el tiempo, en cuyo caso la eficacia de la anulación también será ex tunc salvo que algún principio, como el de protección de la confianza, deba ser tenido en cuenta y determine la eficacia ex nunc de la anulabilidad”. Ibíd., pp. 48

17 Ibid., p. 45.

${ }^{18}$ Ibíd., pp. 45 y 46 "los vicios y defectos que hagan anulable un acto no podrán ser alegados [en sede de recurso] por quienes los hubieren causado". Este precepto "[...] no consagra en modo alguno el principio de que nadie puede invocar la ilegalidad que el mismo ha cometido, pues solo se refiere a los vicios determinantes de la anulabilidad del acto. De este modo, los vicios y defectos que hacen nulo de pleno derecho un acto pueden ser alegados por quien haya causado dicho vicio, incluida, como es lógico, la propia Administración".

19 Ibid., pp. 1-2, sobre la base de las ideas de Santamaría, J., La nulidad de pleno derecho de los actos administrativos. Contribución a una teoría de la ineficacia en el derecho público, Instituto de Estudios Administrativos, Madrid, 1976, pp. 39-79. En el mismo sentido Nieto, A., "Estudio Preliminar", en Beladíez, M., Validez y Eficacia de los actos administrativos, Marcial Pons, Madrid, 1994, pp. 8-25.

${ }^{20}$ Respecto de la estructura de intercambios espontáneos en las relaciones jurídicas privadas, Barros, E., "Lo público y lo privado en el derecho", en Estudios Públicos, núm. 81, 2001, pp. 19-20.

${ }^{21}$ Domínguez, R., Teoría general del negocio jurídico, Editorial Jurídica de Chile, Santiago, 2012, p. 180. 
en el título II del mismo libro, que establece los vicios de que puede adolecer el acto jurídico, y en el párrafo $4^{\circ}$ del título XII del libro II, que regula las prestaciones mutuas. Los continentes indicados contemplan una reglamentación completa para la nulidad, que consiste en reglamentar los más diversos aspectos, a saber:

(1) Causales de nulidad (Art. 1682). Respecto de las que se distinguen las que dan lugar a nulidad relativa, y las que dan lugar a nulidad absoluta (Arts. 1681 y 1682). Complementadas con reglas respectivas al objeto de la obligación (Arts. 1460 a 1466), causa de la obligación (Art. 1467), capacidad de las partes (Arts. 1446 y 1447), y reglamentación de los vicios que puede adolecer el consentimiento (Arts. 1451 a 1458); (2) titularidad de la acción de nulidad, distinguiendo si se trata de nulidad absoluta o relativa (Arts. 1683 y 1684), ineficacia de la renuncia a la acción de nulidad (Art. 1469); (3) posibilidad de declaración de oficio de la nulidad en caso de nulidad absoluta (Art. 1683); (4) confirmación o ratificación de los actos y contratos, en caso que presenten un vicio de nulidad relativa (Arts. 1683, 1684 y 1693 a 1697); (5) plazos de prescripción de la acción de nulidad (Arts. 1683, 1691 y 1692); (6) efectos de la declaración judicial de nulidad, que consiste en dar derecho a las partes para ser restituidas al estado anterior a la celebración del acto o contrato, el que en todo caso es ex tunc (Arts. 1687 y 1689); (7) se establece una distinción respecto de las partes del contrato que no han sido partes en el juicio de nulidad (Art. 1690); (8) se contempla expresamente la regla del nemo auditur qui propriam turpitudinem alegans, que consiste en la restricción que se impone respecto de los causantes del vicio, de alegar o beneficiarse de la nulidad (Arts. 1468 y 1683), y (9) se establece una reglamentación de las prestaciones mutuas en caso de restitución (Arts. 904 y sgts., mediante remisión del Art. 1687).

En el derecho civil chileno respecto de los regímenes típicos de nulidad se distingue entre nulidad absoluta y nulidad relativa. Esta distinción opera sobre la base de las diversas clases de vicios que dan lugar a nulidad. La nulidad absoluta se produce por los vicios de incapacidad absoluta, vicio de objeto o causa, falta de voluntad, y por la omisión de los requisitos o solemnidades que la ley establece para cada acto o contrato en atención con su respectiva naturaleza. Toda otra especie de vicio da lugar a nulidad relativa. Los efectos de una y otra nulidad son idénticos, esto es, dejar a las partes en el mismo estado en que se hallarían si no hubiesen celebrado el acto o contrato nulo. Las diferencias entre una y otra clase de nulidad se refieren a otros aspectos del régimen jurídico, a saber: legitimidad activa, declaración ex officio, plazos de prescripción y convalidación ${ }^{22}$.

Sobre la base del recién enunciado régimen típico de nulidad se ha desarrollado toda una dogmática y jurisprudencia, que se acerca a una configuración técnica acabada, pero que se encuentra lejos del óptimo, debido a que, por una parte, presenta aún inconsistencias provenientes de la importación de categorías dogmáticas galas, que no son necesarias en el ordenamiento jurídico chileno, y por otra parte, como señala

${ }^{22}$ Para la dogmática civil ver, por todos, Alessandri, A., La nulidad y la rescisión en el Derecho civil chileno, Editorial Jurídica de Chile, Santiago, 2008. 
Domínguez, en la concepción tradicional del derecho civil chileno la nulidad tiende a confundirse con la acción de nulidad, es decir, el derecho para atacar el acto, adquiriendo un carácter procesal ${ }^{23}$.

\section{Requerimientos mínimos de un régimen típico de nulidad}

Que nulidad sea un concepto general de aplicación a todo el derecho no implica que siempre deba tener la misma regulación; en otras palabras, no es procedente un régimen unitario de nulidad aplicable a toda clase de actos o negocios jurídicos. El régimen en concreto obedecerá a las características propias de cada clase de actos. Sin embargo, la misma generalidad autoriza a comparar los diversos regímenes existentes, en cuanto a qué regulan, para determinar los elementos comunes que presentan entre sí los diversos regímenes típicos de nulidad.

Respecto del modelo comparado, se debe tener presente, a manera de reserva, que el derecho español consagra un régimen unitario para lo que en el derecho chileno se trata por separado, respecto de los tópicos de nulidad e invalidación administrativa, quedando reservado en el derecho chileno la primera expresión únicamente para la que se declara por los tribunales ${ }^{24}$. Asimismo, la estructura jurídica de contexto es diversa a la chilena, ya que en el derecho español existe una jurisdicción contenciosa administrativa especializada, y una legislación administrativa de mayor densidad. Todo ello se debe considerar al observar dicho régimen típico de nulidad como modelo.

Con relación a lo establecido en el Código Civil se debe tener presente que se trata de un régimen típico de nulidad establecido preferentemente para manifestaciones de la autonomía de la voluntad (poder normativo autónomo), a diferencia de la nulidad en el ámbito público que se refiere a actos que implican el ejercicio de una autoridad heterónoma. En este sentido, la reglamentación típica establecida en el título XX del libro IV del Código Civil (1857) no es un régimen jurídico unitario para la nulidad de los actos jurídicos. En este orden de ideas se señala que "no existe en nuestro derecho una teoría unitaria sobre la nulidad para todos los negocios jurídicos” ${ }^{25}$, cuestión que es más patente respecto del ámbito propio y exclusivamente público, donde no se presenta la bilateralidad o sinalagma para el que se diseñaron las reglas de nulidad del Código Civil.

De modo que, a mi entender, las nulidades públicas y privadas deben establecer regímenes jurídicos diversos en razón de las características de las diferentes clases de actos jurídicos a los que se refieren ${ }^{26}$. Por lo anterior no interesa a este trabajo tratar

${ }^{23}$ Domínguez, R., “Todo el que tenga interés en ello... (sobre el Art. 1683 del Código Civil chileno y el interés para alegar la nulidad absoluta)", en A.A.V.V. Estudios de Derecho Privado en homenaje al profesor Christian Larroumet, Ediciones Fundación Fernando Fueyo, Santiago, 2008, p. 543.

${ }^{24}$ Respecto de la invalidación administrativa ver Millar, J., La potestad invalidatoria en el derecho chileno, cit. passim.

${ }^{25}$ Domínguez, R., Teoría general del negocio jurídico, cit., p. 180.

${ }^{26}$ En un sentido diverso Baraona, J., "La nulidad de los actos administrativos y la nulidad de los actos y contratos del Código Civil: ¿Son tan distintas?”, en Revista Chilena de Derecho Privado, núm. 8, 2007, 59-106. 
el detalle acerca del cómo se ha regulado cada uno de los tópicos en los modelos enunciados, esto es el contenido, solo interesa resaltar que dichos aspectos se encuentran reglamentados expresamente.

Teniendo presente lo antepuesto, de los modelos enunciados (legislación española y Código Civil chileno) en cuanto regímenes típicos, en exclusiva consideración a los aspectos regulados, utilizando el método inductivo se puede determinar que un régimen jurídico exhaustivo para la nulidad administrativa en el ordenamiento jurídico chileno debe considerar los siguientes aspectos:

(1) Un establecimiento claro y preciso de los vicios de legalidad que dan lugar a nulidad.

(2) Una regulación en cuanto a la titularidad de la acción, y las restricciones de la legitimidad activa en virtud de la aplicación del principio nemo auditur.

(3) Declarabilidad ex officio de la nulidad, dependiendo del vicio.

(4) Referirse a la posibilidad de convalidar o no el acto viciado, dependiendo de la entidad del vicio.

(5) Establecer cuál es efecto del tiempo y determinar si se trata de un plazo de saneamiento del vicio o de prescripción de la acción.

(6) Determinar los efectos de la declaración de nulidad, en los aspectos temporal, personal y real.

Determinados estos elementos corresponde ahora contrastar si la nulidad de derecho público, en tanto nulidad administrativa, los contempla.

\section{Dogmática CHILENA DE LA NUlidAD DE DERECHO PÚBlico}

La nulidad en el derecho público chileno es una construcción dogmática diseñada a base de la Constitución Política. De allí que ha adquirido características y una fisonomía propia. Cuestión que ha sido permanente, desde la vigencia de la Constitución de 1833, luego con la Constitución de $1925^{27}$, y ahora bajo la vigencia de la Constitución Política de 1980.

Precisamente el texto constitucional vigente, en el artículo $7^{\circ}$ dispone que "Los órganos del Estado actúan válidamente previa investidura regular de sus integrantes, dentro de su competencia y en la forma que prescriba la ley.

Ninguna magistratura, ninguna persona ni grupo de personas pueden atribuirse, ni aun a pretexto de circunstancias extraordinarias, otra autoridad o derechos que los que expresamente se les hayan conferido en virtud de la Constitución o las leyes.

${ }^{27}$ Respecto de la primera, Hunneus, J., La constitución ante el Congreso, Imprenta de Los Tiempos, Santiago, tomo II, 1879, p. 406. En relación con la segunda, Bernaschina, M., "Bases Jurisprudenciales para una teoría de las nulidades administrativas”, en Boletín del seminario de Derecho público, Universidad de Chile, núm. 45-48, 1949, pp. 549-559. 
Todo acto en contravención a este artículo es nulo y originará las responsabilidades y sanciones que la ley señale”.

Como se sabe, fuera de este precepto constitucional no se encuentra un régimen reglamentado a nivel legislativo de la nulidad de derecho público en lo que se refiere a los actos de la Administración de Estado. Ahora bien, a falta de una reglamentación, la dogmática publicista se ha encargado de perfilar un régimen jurídico para la nulidad administrativa. Todo ese desarrollo dogmático y jurisprudencial constituye la propia teoría de la nulidad en el derecho público chileno. En congruencia con su objeto de análisis, esto es, los actos del poder público, sus postulados consideran aspectos propiamente publicistas de la validez y nulidad, en lo que dice relación con los fundamentos, características, efectos, y campo de aplicación de la institución. A continuación, para mayor claridad de la exposición se divide esta sección en dos partes, a saber: (1) tesis clásica, y (2) revisión de la tesis clásica.

\section{Tesis clásica}

El primer trabajo en que se desarrolla una teoría de la nulidad de derecho público proviene del profesor Mario Bernaschina, quien a mediados del siglo XX comienza a delinear lo que denomina una teoría de las nulidades administrativas ${ }^{28}$, la que construye con base constitucional de acuerdo con preceptos contenidos en la Constitución de 1925 . Bernaschina constata la diferencia entre el actuar público y el privado, de lo que se sigue que los actos del poder público deben tener su propia teoría de la nulidad, diversa de la nulidad de derecho privado ${ }^{29}$. Afirma que como el acto nulo no puede imputarse al órgano, es ineficaz como acto jurídico estatal ${ }^{30}$. Precisando el régimen jurídico, indica que por ningún motivo las partes podrían ratificar el vicio que invalida un acto y que no se sanea ni siquiera por el transcurso del tiempo. Asimismo, señala que no es necesario que la nulidad sea declarada por la autoridad, salvo las excepciones

28 Bernaschina, M., "Bases Jurisprudenciales para una teoría de las nulidades administrativas”, cit. pp. 549-559. Sin perjuicio que se puede encontrar un antecedente remoto en el siglo XIX, Hunneus, J., $L a$ constitución ante el Congreso, cit. pp. 406, quien señalaba que "en cuanto a los decretos que el ejecutivo dictare, arrogándose atribuciones propias de otros poderes, invadiendo atribuciones ajenas, limitando las garantías individuales, ofendiendo algún derecho, o, en general violando la constitución o las leyes, no es menester que su nulidad sea declarada expresamente por alguna autoridad pública".

${ }^{29}$ En este sentido, señala que los órganos del Estado tienen una competencia limitada por el ordenamiento jurídico, y a diferencia de las personas naturales que pueden manifestar su voluntad libremente, las personas que sirven los órganos estatales no pueden comprometerse libremente, porque sus decisiones van a crear normas estatales, "actos jurídicos imputables al órgano mismo y, en definitiva, al Estado". Esta posición se basa en los artículos $4^{\circ}, 23$ y 75 de la Constitución Política de 1925, los que, a su entender "contienen las bases constitucionales para las teorías de las nulidades de derecho público”. Bernaschina, M., "Bases Jurisprudenciales para una teoría de las nulidades administrativas”, cit. pp. 548.

${ }^{30}$ Afirma que el acto nulo no puede producir efecto alguno como acto jurídico, desde el momento en que no puede ser imputable al ordenamiento jurídico, porque ha sido dictado fuera de ese ordenamiento con infracción de las normas jurídicas. Ibid., pp. 557-558. 
expresas que la ley establece, de manera que antes y después de su declaración el acto no puede producir efecto alguno ${ }^{31}$.

De modo que la nulidad sería de eficacia ipso iure, y además imprescriptible ${ }^{32}$. Cabe destacar, desde ya, que serán estos los postulados que trascenderán en cierta medida como los definitorios de la tesis clásica. Respecto de las causales, sostiene que las normas constitucionales demuestran que el acto que exceda la competencia legal o que no observa las formalidades es ineficaz ${ }^{33}$. Por tanto, delimita las causales a los vicios de incompetencia y de forma ${ }^{34}$. En cuanto al ámbito de aplicación de la teoría de las nulidades de derecho público, para este autor, se restringe en exclusiva a la nulidad administrativa $^{35}$. Así, no cabe dentro de la teoría de la nulidad de derecho público la nulidad procesal, ni la nulidad de los actos legislativos, las que al entender de este autor constituyen anulabilidades ${ }^{36}$.

Bajo la vigencia de la Constitución Política de 1980, la doctrina y la jurisprudencia, en atención a la sabida falta de una regulación sistemática, por medio de la interpretación e integración han procedido a delinear un régimen jurídico para la nulidad de derecho público. Así, basado en el artículo $7^{\circ}$ de la Constitución se ha tratado de construir una teoría de la nulidad de derecho público ${ }^{37}$ y se la ha definido como un "mecanismo jurídico sancionador fundamental" 38 , caracterizado como inexistencia ${ }^{39}$, y en consecuencia, no

\section{Ibid.}

${ }^{32}$ Respecto de lo primero hay texto expreso que podría dar lugar a ello en el artículo 23 de la Constitución de 1925, a diferencia de la Constitución Política vigente.

${ }^{33}$ Bernaschina, M., "Bases Jurisprudenciales para una teoría de las nulidades administrativas”, cit. p. 551.

${ }^{34}$ Lo sostiene sobre la base de los artículos $4^{\circ}, 23$ y 75 de la Constitución Política de 1925. Ibíd.

35 Ibid., p. 556.

${ }^{36}$ De modo que "no tiene aplicación general sino que solamente para los actos administrativos". Esta limitación se relaciona con la clasificación de la nulidad de derecho público, en nulidad y anulabilidad. Señala que la primera opera de pleno derecho y que la anulabilidad, que llama también ilegalidad, implica que debe ser declarada. Ibíd., pp. 556 y 557.

${ }^{37}$ A decir de un autor, "la interpretación estricta y exclusivamente gramatical de dicha preceptiva, conduce a propiciar que toda actuación de cualquier órgano del Estado no es válida sino nula, cuando las personas naturales que actúan en las entidades estatales no poseen la investidura regular correspondiente, o cuando perfeccionan actos al margen de su competencia o bien cuando no respetan las formas legales, sin distinción alguna. Consolida esta idea el inciso $2^{\circ}$ que prohíbe actuar al margen de la competencia legal expresa y la prescripción final de la norma que dice todo acto en contravención a este artículo es nulo, lo que importaría que la nulidad lo sería por sí sin necesidad de mayor declaración que esta". Reyes, J., "Reflexiones y bases acerca de la nulidad de Derecho público", en Revista de Derecho de la Universidad Católica de Valparaíso, núm. 17, 1997, p. 393. Aunque se encarga de señalar que esta es la interpretación mayoritaria, de la que disiente. Destacado en original. Soto se refiere a los orígenes históricos de la regla, remarca que se ha establecido ya desde 1833 una sanción específica para aquellos actos que contravengan los requisitos de validez que estipulan los incisos $1^{\circ}$ y $2^{\circ}$ del artículo $7^{\circ}$, Soto, E., "La nulidad de derecho público referida a los actos de la administración”, en Revista de derecho de la Universidad Católica de Valparaíso, vol. 14,1992, p. 419.

38 Soto, E., "La nulidad de derecho público en el derecho chileno", en Revista de Derecho Público, núms. 47- 48, 1990, p. 12.

39 Soto, E., "La nulidad de derecho público: su actualidad", en Revista de derecho de la Universidad Católica de Valparaíso, vol. 18, 1997, p. 353. 
cabrían diversos tipos de nulidad (a diferencia de Bernaschina), ni propugnar la validez del acto viciado mientras no se declare la nulidad ${ }^{40}$. Esta última corriente sostiene que el fundamento de la nulidad de derecho público radica en la supremacía constitucional y la limitación de poderes, todo lo que conlleva a la nulidad, que es entendida luego como inexistencia, y como consecuencia, en su régimen jurídico, es insaneable, imprescriptible y sin necesidad de declaración judicial ${ }^{41}$. Ahora bien, en cuanto a que la nulidad de derecho público no requiere ser declarada por el juez para que exista ${ }^{42}$, esta doctrina sostiene que la Constitución Política declara la nulidad del acto, dictado en su contravención; y el juez solo reconoce ese hecho al declararlo nulo en el respectivo fallo en que acoge la pretensión anulatoria ${ }^{43}$.

\section{Ibid.}

${ }^{41}$ Soto, E., "La nulidad de derecho público: su actualidad", cit. passim. Agrega que al decir la Constitución que "todo acto en contravención a este artículo es nulo" no asume ella la posibilidad que sea nulo en el futuro o que requiera que esa nulidad se produzca solo en la medida que haya pronunciamiento judicial y a partir de tal declaración, sino que es nulo desde el instante en que se incurre en la elaboración o dictación de ese acto, en una contravención a la Constitución, en las exigencias dispuestas para su validez, de allí que la nulidad sea de pleno derecho, vale decir, que se produce por el solo ministerio de la Constitución. Ibíd., pp. 349. Y en otro lugar se señala que "es la propia Constitución la que ha dispuesto esta sanción, sanción que se produce y opera en el mismísimo instante en que se da en la realidad esta contravención”. Soto, E., "La nulidad de derecho público referida a los actos de la administración”, cit. p. 419. El argumento gramatical es criticado por Bocksang, sin embargo que este autor comparte la concepción de la nulidad de derecho público como de pleno derecho, pero con sólidas raíces en el argumento histórico y político. Bocksang, G., "De la nulidad de derecho público como inexistencia”, en Ius Publicum, núm. 16, 2006, pp. 91-116.

42 Soto, E., "La nulidad de derecho público en el derecho chileno", cit. p. 23. Es más, señala que "frente a un acto nulo el afectado debe resistir su cumplimiento y esa resistencia -aún fáctica si es menester y posiblese ha de traducir luego en interponer la acción de nulidad que le confiere el ordenamiento constitucional [...] o la acción de nulidad específica que le confiere el ordenamiento". Ibíd. p. 25.

43 Soto, E., "La nulidad de derecho público: su actualidad", cit. p. 354 . Se puede apreciar como de todos modos se le asigna un papel relevante a la sentencia judicial. Soto complementa el argumento, en orden a que a la declaración judicial si le corresponde cierto rol. En este sentido señala que por razones de seguridad jurídica, precisamente certeza jurídica, por la naturaleza del tráfico jurídico y atendido que nadie puede hacerse justicia por sí mismo, ha de existir una declaración formal e indiscutida de la judicatura. Soto, E., "La nulidad de derecho público referida a los actos de la administración", cit. p. 420. Para ello las personas disponen de la acción de nulidad, "esta acción no es otra que la acción de nulidad, la cual emana precisamente del artículo $7^{\circ}$ inciso $3^{\circ}$ de la Constitución, al prescribir esta de manera expresa este efecto (nulidad) para aquellos actos de los órganos del Estado -en este caso administrativos que hayan sido dictados contraviniendo lo dispuesto por esta disposición-”. Ibíd., p. 421. A mayor abundamiento señala que "hay una falacia en esa pretendida afirmación cual es afirmar una antinomia, porque el que sea de pleno derecho no excluye per se tal declaración judicial; se olvida que no cabe la autotutela en nuestro derecho [...] y, por ende, ni la autoridad ni el particular pueden declarar por sí o ante sí nulo un determinado acto si ello significa una controversia de Derecho". Soto, E., "La nulidad de derecho público: su actualidad", cit. p. 351. En cuanto al rol de la establecida declaración judicial se precisa que esta únicamente reconoce un hecho anterior Ibíd., pp. 351 y 352. A este respecto Fiamma señala que la declaración de nulidad de un acto administrativo es un asunto de carácter jurisdiccional, porque habría una contienda entre un acto de la Administración y el derecho de un particular. De esto se infiere que se requeriría de una declaración judicial y una previa acción para convertir la invalidez en nulidad. Sin embargo, en un trabajo posterior este autor señala que el objeto de la acción constitucional de nulidad es un acto administrativo que no ha cumplido con los requisitos de validez contemplados en los incisos 1 y 2 del artículo $7^{\circ}$ "y su finalidad será 
Respecto de las causales de nulidad, se señala que el objeto de la acción de nulidad es el acto que se pretende irregular en cuanto al cumplimiento de los requisitos de validez exigidos por la Constitución ${ }^{44}$, en este sentido se indica que el sistema de nulidades de derecho público está previsto en el artículo $7^{\circ}$ de la Constitución y procede en los supuestos que en él se establecen. Esto es, los vicios de investidura regular, competencia y forma ${ }^{45}$.

Respecto de la acción de nulidad, se le ha tratado como acción constitucional de nulidad. Se sostiene que del acoplamiento entre el artículo $19 \mathrm{~N}^{\circ} 3$ y el artículo $7^{\circ}$ inc. III, nace la acción constitucional de nulidad ${ }^{46}$, que hace realidad el principio de legali$\operatorname{dad}^{47}$, definiéndose como "un poder o una facultad de accionar ante los tribunales que tiene toda persona pretendiendo la nulidad de un acto administrativo" ${ }^{48}$.

En cuanto a los titulares de la acción se señala que la nulidad de derecho público ampara el imperio de la ley, el derecho objetivo ${ }^{49}$; en consecuencia, cualquier persona queda legitimada para accionar por el cumplimiento de la legalidad aun cuando su único interés sea el derecho a vivir bajo el imperio de la ley ${ }^{50}$.

el reconocimiento y declaración judiciales de la nulidad constitucionalmente preexistente que lo invalida de pleno derecho, inicial y perpetuamente". Fiamma, G., "Acción constitucional de nulidad y legitimación activa objetiva”, en Revista de Derecho Público, núm. 49, 1991, p. 92.

${ }^{44}$ Fiamma, G., “Acción constitucional de nulidad y legitimación activa objetiva”, cit., p. 95.

45 Además, Fiamma aparentemente se refiere tanto al principio de juridicidad como a las causales del artículo $7^{\circ}$ de la Constitución Ibíd., p. 97. En el mismo sentido Soto, aunque parece restringirlo a las causales del artículo $7^{\circ}$, esto es, investidura, competencia y forma. Ahora bien, este último autor se refiere a un concepto amplio de competencia referido a la habilitación legal. En este orden de ideas Soto señala que los vicios se refieren (1) a la investidura del autor del acto, v.gr. nombramientos o designaciones que no se han conformado con la Constitución y las leyes; (2) a la competencia, donde caben, por ejemplo: ausencia de atribución, ausencia de motivo, entendido como el hecho/necesidad pública que mueve a actuar para satisfacerla, errada calificación jurídica del hecho, error en la apreciación de los hechos, ausencia de razonabilidad en el ejercicio de la potestad, desviación de fin, y (3) a la forma que prescriba la Constitución o la ley, como la infracción al debido procedimiento legal (sea por alteración de trámites, omisión de ellos, exigencia de algunos sin que estén legalmente previstos) desviación de procedimiento, incumplimiento de las formas exigidas en el acto terminal. Soto, E., "La nulidad de derecho público referida a los actos de la administración”, cit. pp. 422 y 423.

46 Fiamma, G., "La acción constitucional de nulidad: un supremo aporte del constituyente de 1980 al Derecho Procesal Administrativo", cit., p. 126.

${ }^{47}$ Ibid., p. 127, en sus palabras, "pilar indispensable de todo Estado que quiera llamarse de derecho".

${ }^{48}$ Ibíd., p. 126. Argumenta que el derecho a la acción, derivado del art. $19 \mathrm{~N}^{\circ}$ 3, es el vehículo lógico que requería el artículo $7^{\circ}$. En efecto, si la nulidad para que se produzca requiere ser declarada, declaración que corresponde precisamente al juez, la vía lógica para transportar a los tribunales la nulidad a que se refiere el precepto citado es el derecho a la acción. Ibíd.

${ }^{49}$ Fiamma, G., “Acción constitucional de nulidad y legitimación activa objetiva”, cit., p. 94.

${ }^{50}$ Ibíd., p. 95. Se complementan estos argumentos señalando que el artículo $7^{\circ}$ de la Constitución también confiere una excepción de nulidad, la que define como "medio procesal que tiene todo aquel a quien se pretende exigir por la Administración, y ante los tribunales, una determinada prestación que tiene por fundamento un acto administrativo viciado de nulidad por no haberse atenido a las exigencias que la propia Constitución establece en dicha disposición". Soto, E., "La nulidad de derecho público referida a los actos de la administración”, cit. p. 421. 
Del modo anteriormente descrito, la nulidad de derecho público se ha definido como "un mecanismo jurídico sancionador fundamental del derecho público. Consistiría en la ineficacia de los actos estatales dictados en contravención al principio de juridicidad contemplado en los artículos $6^{\circ}$ y $7^{\circ}$ de la Constitución Política de la República" ${ }^{\text {}}$. Concepto de la tesis clásica descrito por $\mathrm{Jara}^{52}$ y sustentada por Soto ${ }^{53}$, seguida en la actualidad por Bocksang ${ }^{54}$. De modo que, en esta descripción, la nulidad de derecho público presenta un alcance de cláusula general de anulación de actos administrativos ejecutados en ejercicio de una potestad pública.

\section{Revisión de la tesis clásica}

Las nuevas ideas acerca de la institución, en lo sustancial divergen de la tesis clásica en la postura de que la nulidad no operaría de pleno derecho, en el tópico de la prescriptibilidad, y en establecer que no cualquier vicio que afecte el principio de legalidad en el actuar de los órganos del Estado constituye un vicio que dé lugar a nulidad ${ }^{55}$. Así, dentro de la dogmática administrativa cabe distinguir posiciones diversas a la sostenida por la tesis clásica, que se refieren a estos aspectos.

Respecto de la prescripción de la acción de nulidad es importante consignar la doctrina jurisprudencial que, no obstante continuar entendiendo a esta como imprescriptible (al menos retóricamente), resuelve que sus efectos patrimoniales se encuentran sujetos a las reglas generales de prescripción establecidas en el Código Civil ${ }^{56}$. Dicha concepción

${ }^{51}$ Jara, J., La nulidad de derecho público ante la doctrina y la jurisprudencia, Editorial Libromar, Santiago, 2004 , p. 29, quien se refiere a lo establecido por la tesis clásica.

52 Ibid.

53 Soto, E., "La nulidad de derecho público en el derecho chileno", cit. pp. 11-25.

${ }^{54}$ Bocksang, G., "De la nulidad de derecho público como inexistencia”, cit. pp. 91-116.

55 Entre otros, cfr. Acuña, M., "La naturaleza de la nulidad de derecho público", en Revista de Derecho, Universidad de Concepción, núm. 212, 2002, pp. 373-390. Bermúdez, J., "Estado actual del control de legalidad de los actos administrativos: ¿qué queda de la nulidad de derecho público?”, en Revista de Derecho, Universidad Austral, vol. 23, núm. 1, 2010, pp. 103-123. Jara, J., La nulidad de derecho público ante la doctrina y la jurisprudencia, cit., Letelier, R., "Un mal día no es eterno: Seis alcances en materia de invalidación y nulidad de los actos administrativos", en Revista de Derecho, Universidad de Concepción, núm. 212, 2002, pp. 691-728. Pierry, P., "La nulidad en Derecho Administrativo", en Revista de Derecho de la Universidad Católica de Valparaíso, núm. 15, 1994, pp. 79-100. Reyes, J., "Reflexiones y bases acerca de la nulidad de Derecho público", cit. pp. 383-405. En las antípodas Silva Cimma señala que los artículos " $\mathrm{N}^{\text {os }} 7^{\circ}$, incisos $2^{\circ}$ y $3^{\circ}$, y 35 , inciso $1^{\circ}$, respectivamente, más que preceptos específicos de donde se pueda deducir claramente una teoría sobre la nulidad de los actos administrativos, constituyen simplemente normas de llamado de atención para el legislador y el administrador". En general la doctrina publicista con base constitucional ha generado nuevas aproximaciones a la nulidad de derecho público que sí le reconocen valor normativo. Silva, E., Derecho Administrativo chileno y comparado. Actos, contratos y bienes, Editorial Jurídica de Chile, Santiago, 1995, p. 150.

${ }^{56} \mathrm{La}$ jurisprudencia se ha uniformado en este sentido desde el fallo de la causa Aedo con Fisco, en sentencia de la Corte Suprema, rol núm. 852-2000, 27 de noviembre de 2000. En el mismo sentido, Corte Suprema, rol núm. 4.469-2000,14 de mayo de 2002; Corte Suprema, rol núm. 667-2007, 31 de marzo de 2008; Corte Suprema, rol núm. 1672-2007, 26 de junio de 2008. Sobre esta materia cfr. Concha, R. 
implica que el efecto propio de la nulidad, esto es, el devolver las cosas al estado anterior a la dictación del acto nulo, se encuentra limitado por los plazos de prescripción.

Con relación a las causales de nulidad, se ha sostenido que no cualquier vicio que afecte el principio de juridicidad en el actuar de los órganos del Estado acarree nulidad, sino que los expresados en el artículo $7^{\circ}$ de la Constitución ${ }^{57}$. En cuanto al vicio de legalidad material o vulneración del principio de juridicidad, la Corte Suprema ha limitado las causas de la nulidad a los vicios de investidura, competencia y de forma, establecidos en el artículo $7^{\circ}$ de la Constitución, excluyendo el irrespeto de la legalidad material de las causales y, en consecuencia, restándose de la nulidad de derecho público el carácter de cláusula general de anulación por vulneración del principio de legalidad ${ }^{58}$. Como una posibilidad de contemplar a la legalidad material como causal de nulidad se ha planteado la posibilidad de aplicar el artículo 1462 del Código Civil, que establece que hay un objeto ilícito en todo lo que contraviene al derecho público chileno, en el sentido de lo sostenido por Bermúdez, de hallar la vulneración a la legalidad material en dicha regla, mediante remisión dada por los artículos $6^{\circ}$ y $7^{\circ}$ de la Constitución ${ }^{59}$.

Por otra parte, cabe señalar que la doctrina ha reparado que el establecimiento en la Ley $\mathrm{N}^{\circ} 19.880$ de 2003 , de que no cualquier vicio de forma afecta la validez, da pie para explorar si acaso es posible entender que el artículo $7^{\circ}$ de la Constitución no toca plenamente al acto jurídico administrativo al menos en cuanto a su validez formal, ya que por los términos de dicho precepto cualquier vicio de forma, independientemente de su índole, afectaría la validez de la actuación. En este sentido, cabe destacar que Jara ha planteado la introducción del principio de conservación de los actos administrativos

\footnotetext{
"Aplicación de reglas civiles en derecho administrativo, especialmente en materia de prescripción de la acción de nulidad”, en Revista de Derecho, Universidad de Concepción, año 77, núm. 225-226, 2009, pp. 197-211.

57 Acuña, M., "La naturaleza de la nulidad de derecho público", cit. pp. 385: "en efecto, la nulidad aparece tan solo en el inc. $3^{\circ}$ del artículo siguiente, el $7^{\circ}$, y nótese bien, no como sanción a la infracción del artículo $6^{\circ}$, sino como consecuencia a la contravención de lo previsto en los incs. $1^{\circ}$ y $2^{\circ}$ del mismo artículo $7^{\circ}$ - "todo acto en contravención a este artículo es nulo"-, normas que establecen los requisitos para la actuación de los órganos estatales si lo que se quiere es dictar actos válidos (destacado en original)-. En concordancia con la doctrina, para Acuña en el artículo $6^{\circ}$ se establece el principio de juridicidad, pero su infracción no necesariamente tiene por efecto la nulidad, sino que solo cuando cabe en los supuestos del artículo $7^{\circ}$. En el mismo sentido, Reyes, J., "Reflexiones y bases acerca de la nulidad de Derecho público”, cit. pp. 394407 señala que disiente "del juicio de que la nulidad de derecho público en Chile opera siempre de pleno derecho y más aun que cualquier vicio que afecte el principio de legalidad en el actuar de los órganos del Estado acarrea nulidad".

${ }^{58}$ Corte Suprema, rol núm. 31132-2005, 28 de junio de 2006, y desde ahí en adelante. Recientemente la Corte Suprema aparentemente ha ampliado los vicios que dan lugar a nulidad en relación con los elementos de acto administrativo, incluyendo vicios en el fin y en los motivos, y además ilegalidad en cuanto al objeto. Corte Suprema, rol núm. 7188-2009, 16 de enero de 2012.

${ }^{59}$ Bermúdez, J., "El principio de legalidad y la nulidad de derecho público en la Constitución Política. Fundamentos para la aplicación de una solución de Derecho Común”, en Revista de Derecho Público, vol. 70, 2008 , pp. 273-285. En sentido similar (pero con diverso fundamento) para los fundamentos de la aplicación del Código Civil en materia de nulidad en la contratación administrativa, Concha, R., Nulidad del contrato de la Administración. Aplicabilidad de las reglas civiles, Thomson Reuters, Santiago, 2012.
} 
en la dogmática de la nulidad administrativa ${ }^{60}$, a lo que cabe agregar la citada base legal del artículo 13 de la Ley $\mathrm{N}^{\circ} 19.880$ de 2003. En virtud de la citada regla, a pesar de ser un determinado acto irregular, este no se anula si se puede cumplir con el fin del acto ${ }^{61}$, de modo que, según se afirma, lo que determina la invalidez de un acto administrativo no es la mera ilegalidad, sino que dicha ilegalidad imposibilite obtener un fin que el ordenamiento jurídico considera objeto de protección ${ }^{62}$.

Respecto de la titularidad de la acción de nulidad, ha estado lejos de concebirse como de legitimidad activa objetiva, a este respecto la jurisprudencia ha entendido que la titularidad de la acción le corresponde a quien se le ha vulnerado un interés, el que la jurisprudencia ha configurado como un derecho ${ }^{63}$. De modo que la legitimidad activa en materia de acción de nulidad, en términos prácticos, únicamente le corresponde a quien se le han lesionados sus derechos subjetivos.

\section{INSUFICIENCIAS DE LA DOGMÁTICA DE LA NULIDAD DE DERECHO PÚBLICO}

En primer lugar aparece una deficiencia conceptual, a saber, en cuanto al carácter de inexistencia que se atribuye por la doctrina clásica a la nulidad de derecho público, lo que tendría por consecuencia en el régimen jurídico que la nulidad operaría de pleno derecho, ab initio y sería insaneable e imprescriptible. A este respecto cabe hacer presente que se incurre en una imprecisión, pues la teoría de la inexistencia, y el cómo opera la nulidad, de pleno derecho o mediante sentencia judicial, son tópicos distintos. El problema de la inexistencia radica en establecer si en el artículo $7^{\circ}$ de la Constitución se establece como consecuencia de la invalidez, diversa de la nulidad, lo que constituye un problema mal planteado, porque precisamente la teoría de inexistencia tiene su origen para explicar supuestos de invalidez que no estén contemplados en una causal de nulidad (por las consecuencias de la aplicación del principio de que no hay nulidad sin texto, en

\footnotetext{
${ }^{60}$ Jara, J., La nulidad de derecho público ante la doctrina y la jurisprudencia, cit., pp. 125 y sgts.

${ }^{61}$ Ideas desarrolladas en el derecho español por Beladíez, M., Validez y Eficacia de los actos administrativos, Marcial Pons, Madrid, 1994.

${ }^{62}$ Jara, J., La nulidad de derecho público ante la doctrina y la jurisprudencia, cit., p. 128. Bermúdez, J., "Estado actual del control de legalidad de los actos administrativos: ¿qué queda de la nulidad de derecho público?” cit., pp. 107-109, donde se le denomina "ilegalidad tolerada". Al respecto, se ha señalado que la Ley N 19.880 de 2003 contiene un principio de "permanencia o conservación de los actos jurídicos administrativos. Es decir, si bien para la ley no resulta indiferente la ilegalidad del acto administrativo, no permitirá la extinción del mismo por cualquier vicio, sino que es exigible la concurrencia de ciertos requisitos para afectar la validez del acto”. Bermúdez, J., Derecho Administrativo General, Legalpublishing Abeledo-Perrot, Santiago, 2010, p. 99. Ahora bien, se señala que la aplicación del principio de conservación tiene ciertos límites: (1) que se trate de vicios de forma en actos reglados (no discrecionales), y (2) que no implique desviación de poder. Beladíez, M., Validez y Eficacia de los actos administrativos, cit., pp. 189 y sgts.

${ }^{63}$ Ferrada, J.C., "Nuevas restricciones a la nulidad de derecho público como proceso administrativo: una jurisprudencia interesante, pero inconsistente”, en Anuario de Derecho Público, Universidad Diego Portales, 2010, pp. 189-203 y jurisprudencia allí referida.
} 
el derecho francés), y precisamente se propugna para aquellos casos que no tengan una causal de nulidad, no para convertir una causal de nulidad en inexistencia ${ }^{64}$. Por otra parte, el problema de la nulidad de pleno derecho se refiere a si nulidad establecida como tal, requiere o no declaración judicial para operar en el medio institucional.

En segundo lugar, teniendo presente el modelo de régimen de nulidad ya expuesto (supra II.3), se presentan las siguientes deficiencias en cuanto al estatuto anulatorio.

Del examen de la teoría de la nulidad de derecho público se puede constatar que, a base de regla expresa, hay acuerdo en la dogmática únicamente sobre que la nulidad tiene una base constitucional y que se encuentra construida, al menos, para el poder público administrativo heterónomo. En los demás aspectos se presentan divergencias relevantes. Como se sabe, tesis clásica atribuyó a la nulidad las características de operar de pleno derecho, causalidad amplia, además de ser imprescriptible, y presentar legitimidad activa objetiva. Sin embargo, el único aspecto en que coinciden plenamente los planteamientos de la tesis clásica expuesta por sus autores más representativos ${ }^{65}$ es en la imprescriptibilidad de la acción de nulidad, discrepando en tópicos tan determinantes como lo es el campo de aplicación de la teoría (cuestión en la que se reparará más adelante).

En cuanto al establecimiento de los vicios de legalidad que dan lugar a nulidad: se constata que sin perjuicio de estar dotado de causales típicas de nulidad, carece de una cláusula general de nulidad por infracción a la legalidad, lo que ha llevado a que la jurisprudencia haya desechado la contravención de la legalidad material como causal de nulidad. Al respecto un autor ha argumentado por la aplicación del artículo 1462 del Código Civil, que dispone una causal de nulidad absoluta por la contravención al derecho público chileno, para de esa manera contemplar la infracción a la legalidad material, por medio de la remisión a ley establecida en los artículos $6^{\circ}$ y $7^{\circ}$ de la Constitución ${ }^{66}$. Sin embargo, respecto de este planteamiento se presenta la dificultad que la Constitución no se remite al Código Civil, esto porque el artículo $6^{\circ}$ de la Constitución se refiere a las sanciones que determine la ley, y es controvertido que la nulidad sea efectivamente una sanción ${ }^{67}$. Por su parte, el artículo $7^{\circ}$ de la Constitución se remite a la ley, señalando que ella debe determinar las responsabilidades y sanciones para los supuestos de nulidad que contempla, no para que esta agregue otra hipótesis de nulidad ${ }^{68}$.

A mi juicio, en relación con los elementos de validez que señala el inciso I del artículo $7^{\circ}$, estos no son taxativos en cuanto requisitos de validez, pues es prácticamente imposible expresar o formular todas las condiciones necesarias y conjuntamente suficientes de

\footnotetext{
${ }^{64}$ Respecto de diversas concepciones de inexistencia ver Guarinoni, R., "De lo que no hay. La inexistencia jurídica", en Doxa, núm. 25, 2002, pp. 637-656.

${ }^{65}$ Fiamma y Soto respecto de Bernaschina.

${ }^{66}$ Bermúdez, J., "El principio de legalidad y la nulidad de derecho público en la Constitución Política. Fundamentos para la aplicación de una solución de Derecho Común”, cit. pp. 273-285.

${ }^{67}$ Delgado, J. “¿'Sanción de invalidez’? Los conceptos de invalidez y de sanción”, en id. “Las nulidades de los contratos: un sistema en evolución”, Editorial Aranzadi, Navarra, 2007, pp. 189-136.

${ }^{68}$ En general sobre el artículo 1462 CC, y en especial respecto de su relación con la nulidad de derecho público, cfr. Concha R., "El objeto ilícito contrario al derecho público, art. 1462 del Código Civil”, en Estudios de Derecho Civil V, LegalPublishing, Santiago, 2010, pp. 79-90.
} 
validez para un determinado acto. En cuanto causales de nulidad, acerca de si estas son, en primer lugar, todas y, en segundo lugar, necesariamente cada una de las causales de nulidad, respecto de lo primero, si solo se trata de estas causales (las establecidas en el Art. $7^{\circ}$ ), la nulidad de derecho público no resuelve todas las vulneraciones al principio de legalidad. Relativo a lo segundo, cabe considerar lo que se ha señalado en cuanto a los vicios de procedimiento y de forma, en relación con el artículo 13 de la Ley $\mathrm{N}^{\circ} 19.880$ de $2003^{69}$. En este contexto, los aspectos expresados en el artículo $7^{\circ}$ no son todos y cada uno de los requisitos de validez de un acto administrativo, en cambio, en cuanto su procedencia como causales de nulidad, a mi entender, estos enunciados sí son típicos ${ }^{70}$.

Referente a la regulación de la titularidad de la acción, y a las restricciones de la legitimidad activa en virtud de la aplicación del principio nemo auditur, no se contemplan preceptos que se refieran a la legitimidad activa para alegar la nulidad en sede jurisdiccional. Para la jurisprudencia se puede apreciar cómo entiende la titularidad de la acción de manera restringida, aún más que en el régimen de derecho civil. Por otro lado no se ha propuesto ni dogmática ni jurisprudencialmente la aplicabilidad del principio de que nadie puede aprovecharse de su propia torpeza o dolo.

Con relación a la posibilidad de la declaración de oficio de la nulidad, dependiendo del vicio, únicamente un autor de la tesis clásica se ha referido a este tópico, recurriendo a los criterios establecidos en las reglas civiles, y señala que procede declarar de oficio la nulidad cuando en un acto administrativo aparezca de manifiesto, considerando que es un principio general del derecho, no obstante encontrarse en el Código Civil ${ }^{71}$.

Respecto de la prescripción de la acción de nulidad, sin embargo de continuar entendiéndose como imprescriptible, la jurisprudencia tiene establecido que los efectos patrimoniales se encuentran sujetos a las reglas generales de prescripción establecidas en el Código Civil. De modo que el efecto de la declaración de nulidad, en el aspecto temporal, se encuentra modulado por la jurisprudencia en el sentido de que se puede interpretar tanto como ex nunc extendido, o desde otra perspectiva como ex tunc restringido a los plazos de prescripción ${ }^{72}$.

69 En este orden de ideas se apunta que las modificaciones legislativas y las nuevas tendencias jurisprudenciales han terminado por desdibujar la formulación original de la nulidad de derecho público. Bermúdez, J., "Estado actual del control de legalidad de los actos administrativos: ¿qué queda de la nulidad de derecho público?" cit., pp. 103-123. Precisamente señala que "Esta situación es posible de ser apreciada en tres ámbitos. En primer lugar, en la inclusión de una especie de ilegalidad tolerada, a partir de la entrada en vigor de la Ley $\mathrm{N}^{\circ} 19.880$, en que solo es un vicio del acto administrativo aquel que, ocurrido durante el procedimiento, tiene alguna entidad o importancia. En segundo término, el retroceso del recurso de protección como paliativo a un contencioso-administrativo, sobre todo a partir del resultado imprevisible del examen de admisibilidad. Finalmente, en la jurisprudencia, la cual ha desmembrado casi por completo la nulidad".

${ }^{70}$ Aunque la forma se halla cuestionada. Ibíd.

71 "En consecuencia el juez debe declarar la nulidad en tal caso pues tal acto contraviene el derecho público chileno (Arts. 1683 en relación con el 1682 y 1462)”. Soto, E., "La nulidad de derecho público referida a los actos de la administración”, cit. p. 423.

72 En todo caso dicha concepción no es original de nuestro sistema, pues en el sistema civil español se establece una solución similar, al respecto Díez-Picazo señala que "el carácter imprescriptible de la acción de nulidad debe entenderse respecto de la declaración de nulidad, pero no por lo que se refiere a las 
En tercer lugar, se verifica el problema no resuelto acerca de la extensión, es decir, cuál es el campo de aplicación de la teoría de la nulidad de derecho público, el que presenta un contenido pacífico y otro controvertido. El primero: la nulidad de derecho público constituye pacíficamente el régimen de nulidad de los actos de la Administración del Estado. El segundo: sin embargo se discute la aplicación a otros ámbitos de la actuación estatal ${ }^{73}$.

En cuanto a lo primero, dentro del campo pacífico de aplicación (la actuación de la Administración del Estado) se presenta un problema respecto de la actividad contractual administrativa, en la que tanto el derecho civil así como el derecho administrativo confluyen en la configuración de su validez ${ }^{74}$. La nulidad de derecho público es adecuada al núcleo público que se encuentra en todo contrato de la Administración, sin embargo, ello no ocurre con relación al elemento propiamente convencional allí presente.

Según las características de los actos sobre los que recae, la nulidad de derecho público en su régimen jurídico considera que su objeto son actos que implican el ejercicio de potestades públicas, ejecutados por sujetos calificados, que operan sobre la base de procedimientos reglados, y que deben satisfacer el interés público. Ahora bien, que la nulidad de derecho público esté diseñada para la nulidad de actos unilaterales y heterónomos, como son los actos del poder público, conlleva que esta construcción dogmática no se presente exhaustiva a la actividad contractual de la Administración del Estado. Lo anterior, toda vez que la nulidad de derecho público, en tanto nulidad administrativa, se orienta a privar de eficacia a actos normativos heterónomos que regulan a un Administrado, y no a una convención celebrada con una contraparte, respecto del que la Administración presenta la calidad de acreedor o deudor o recíproco. Así, la teoría de la nulidad de derecho público, por aptitud y régimen no reconoce el elemento convencional presente en la actividad contractual de la Administración, de allí que no represente un régimen adecuado de nulidad para la contratación administrativa ${ }^{75}$.

cosas que hubiesen sido dadas, entregadas u obtenidas en virtud del contrato nulo. Los efectos restitutorios están sometidos al plazo normal de prescripción de las acciones personales que es el de quince años (Art. 1964), así como la posibilidad de que las cosas sean usucapidas, mediante una usucapión ordinaria si en el usucapiente concurren la buena fe y el justo título, o mediante una usucapión extraordinaria”. Diez-Picazo, L., Fundamentos de Derecho civil patrimonial, Editorial Tecnos, Madrid, 1983, p. 314.

${ }^{73}$ Ya desde antes de la tesis que hemos llamado clásica, se limitaba el alcance de la nulidad de derecho público a los actos de la administración. Así Hunneus en el siglo XIX se refiere al ejecutivo, limitando el alcance a los actos administrativos bajo la vigencia de la Constitución de 1833. Hunneus, J., La constitución ante el Congreso, cit. p. 406. Luego Bernaschina fue enfático al señalar que la teoría se aplica a la nulidad de los actos de la administración, dejando fuera las otras clases de actos. Bernaschina, M., Bases Jurisprudenciales para una teoría de las nulidades administrativas, cit. pp. 551-552.

${ }^{74}$ Concha, R., Nulidad del contrato de la Administración. Aplicabilidad de las reglas civiles, cit. pp. 35-93.

75 Sobre este tópico ver Ibíd. pp. 158-183. 
En cuanto a lo segundo (el campo controvertido de aplicación), se ha sostenido que el artículo $7^{\circ}$ es aplicable a toda la actuación jurídica del Estado ${ }^{76}$. En sentido diverso ${ }^{77}$, ya desde el origen la construcción dogmática de la nulidad de derecho público, se descarta el alcance de la misma a la nulidad procesal, en este sentido se ha escrito que no cabe aplicar las reglas de las nulidades de derecho público a las decisiones de los tribunales, porque se opondrían al imperio y a la independencia total que se ha querido revestir a la judicatura por las normas positivas ${ }^{78}$, aunque recientemente se ha actualizado la controversia $^{79}$. A mi entender, no obstante ser indudable que el artículo $7^{\circ}$ es aplicable a todos los órganos del Estado, en el caso del ámbito jurisdiccional se deben respetar los sistemas de incidentes y recursos que la ley establece para hacer valer la nulidad, por lo que no sería procedente la aplicabilidad de la teoría de la nulidad de derecho público a la nulidad procesal, ya que los citados mecanismos son los que establece la ley procesal para depurar del proceso los actos inválidos ${ }^{80}$. Cuestión que a mi entender es coherente, ya que para cada tipo de acto el ordenamiento jurídico establece un sistema ad hoc de nulidades, de acuerdo con la naturaleza o características propias de cada acto o contrato.

En relación con el modelo planteado para un régimen exhaustivo de nulidad (supra II.3), se constata que la mayoría de los aspectos a regular se le ha dotado de contenido por la doctrina y la jurisprudencia, sin perjuicio que en algunos tópicos, en los que incluso

${ }^{76}$ En este sentido Soto se señala que es “inconstitucional pretender que este precepto (art. $7^{\circ}$ inciso $3^{\circ}$ en relación con sus incisos $1^{\circ}$ y $2^{\circ}$ precedentes) no fuera aplicable a algún acto de alguna autoridad estatal y pudiera, en consecuencia, escapar a su imperatividad y operatividad directa (art. $6^{\circ}$ inciso $2^{\circ}$ ). Bajo esta disposición está tanto el acto constituyente que lo viola, como cualquier acto legislativo o de órgano parlamentario (lato sensu), jurisdiccional, administrativo y contralor que lo contraviene". Soto, E., "La nulidad de derecho público: su actualidad", cit. p. 348.

77 En cuanto a los actos del poder legislativo, se señala que respecto de los dictados "fuera de la competencia del órgano respectivo, tampoco puede hablarse de nulidad. Las constituciones han creado un recurso especial, cuyos efectos están determinados por ellas mismas. Es el llamado recurso de inconstitucionalidad o inaplicabilidad de las leyes", Bernaschina, M., "Bases Jurisprudenciales para una teoría de las nulidades administrativas", cit. p. 552. Sobre este punto en específico no ha existido controversia relevante.

${ }^{78}$ Ibid. y agrega que "en efecto, existen reglas especiales que han dado origen a una nulidad también especial, la llamada nulidad procesal, que impide aplicarle las reglas que hemos deducido de los artículos $4^{\circ}, 23$ y 75 de la Constitución Política”.

${ }^{79}$ Otero, M., La nulidad procesal civil, penal y de derecho público, Editorial Jurídica de Chile, Santiago, 2010, pp. 269-270, plantea la "nulidad procesal de derecho público". Cabe encontrar algún fallo que ha aplicado la teoría de la nulidad de derecho público en materia procesal, Corte de Apelaciones de Talca, rol laboral 42-2009, 9 de octubre de 2009, resolución en que se declaró nula de derecho público una sentencia definitiva de primera instancia, a pesar de que se habían interpuesto recursos procesales de casación y apelación. Este problema se planteó reiteradamente a propósito de la antigua y ya derogada jurisdicción tributaria, con respecto a la delegación de facultades de juez tributario, ver, por ejemplo Corte de Apelaciones de Concepción, rol núm. 156-1999, 13 de octubre de 2006.

${ }^{80}$ Para la nulidad procesal se establece un sistema completo de incidentes y recursos, al respecto, Tavolari, R., "La nulidad procesal en el derecho actual", en A.A.V.V. El proceso en acción, Editorial Libromar, Santiago, 2000, pp. 243-278 y Carrasco, J., "La nulidad procesal como técnica protectora de los derechos y garantías de las partes en el derecho procesal chileno", en Revista de Derecho, Universidad Católica de Norte, año 18, núm. 1, 2011, pp. 49-84. 
falta regla expresa, se presenta además carencia de discusión relevante, y por lo tanto la falta de un régimen determinado ya sea por la doctrina o bien por la jurisprudencia: declarabilidad ex officio, y restricción de la acción o de los beneficios de la declaración de nulidad mediante el principio nemo auditur.

\section{Conclusión}

La teoría de la nulidad de derecho público en tanto nulidad administrativa se ha construido para depurar del ordenamiento jurídico actos heterónomos y unilaterales del poder público. Ahora bien, concebida como inexistencia, se encuentra medianamente vigente en la argumentación de nuestros tribunales. Sin embargo se trata de una vigencia más bien retórica. Lo anterior, ya que la configuración de la nulidad de derecho público contemplada en el núcleo dogmático constitucional transitó de ser una cláusula general de anulación, a que como causales de nulidad se consideren exclusivamente los vicios establecidos en el artículo $7^{\circ}$, excluyendo la legalidad material, y reconociendo la prescriptibilidad de las consecuencias patrimoniales de la misma.

Al contrastar el modelo considerado en este trabajo con lo construido por la doctrina y la jurisprudencia se aprecia que no se ha terminado de delinear un régimen jurídico para la nulidad de derecho público, en tanto nulidad administrativa. Sin embargo que de lo expuesto se puede apreciar una configuración del régimen jurídico de la institución, estatuto que al ser mayormente jurisprudencial se encuentra sujeto a los vaivenes propios de un sistema donde las sentencias están dotadas únicamente de efecto relativo.

En los aspectos más críticos, hace falta una reglamentación expresa que se refiera a lo menos a los tópicos de: (1) titularidad de la acción y sus limitaciones; (2) declarabilidad ex officio de la nulidad, y (3) prescripción.

\section{BIBLIOGRAFÍA}

Acuña, M., "La naturaleza de la nulidad de derecho público", en Revista de Derecho, Universidad de Concepción, núm. 212, 2002, pp. 373-390.

Alessandri, A., La nulidad y la rescisión en el Derecho civil chileno, Editorial Jurídica de Chile, Santiago, 2008.

Baraona, J., "La nulidad de los actos administrativos y la nulidad de los actos y contratos del Código Civil: ¿Son tan distintas?”, en Revista Chilena de Derecho Privado, núm. 8, 2007, pp. 59-106.

Barros, E., "Lo público y lo privado en el derecho", en Estudios Públicos, núm. 81, 2001, pp. 5-37. BeladíEz, M., Validez y Eficacia de los actos administrativos, Marcial Pons, Madrid, 1994.

BeLAdíEz, M., "La nulidad y la anulabilidad. Su alcance y significación”, en Revista de Administración Pública, núm. 133, 1994, pp. 155-187.

Bermúdez, J., "El principio de legalidad y la nulidad de derecho público en la Constitución Política. Fundamentos para la aplicación de una solución de Derecho Común”, en Revista de Derecho Público, vol. 70, 2008, pp. 273-285. 
Bermúdez, J. "Estado actual del control de legalidad de los actos administrativos: ¿qué queda de la nulidad de derecho público?, en Revista de Derecho, Universidad Austral, vol. 23, núm. 1, 2010, pp. 103-123.

Bermúdez, J., Derecho Administrativo General, LegalPublishing Abeledo-Perrot, Santiago, 2010.

Bernaschina, M., "Bases Jurisprudenciales para una teoría de las nulidades administrativas", en Boletín del seminario de Derecho público, Universidad de Chile, núm. 45-48, 1949, pp. 549- 559.

Bocksang, G., "De la nulidad de derecho público como inexistencia”, en Ius Publicum, núm. 16, 2006, pp. 91-116.

Cano, T., "La invalidez de los actos administrativos y sus consecuencias", en Revista General de Derecho Administrativo, núm. 8, 2005, pp. 1-51. [Fecha de consulta: 20 de diciembre de 2011, disponible en www.iustel.com.]

Carrasco, J., "La nulidad procesal como técnica protectora de los derechos y garantías de las partes en el derecho procesal chileno", en Revista de Derecho, Universidad Católica de Norte, año 18, núm. 1, 2011, pp. 49-84.

CONCHA, R. "Aplicación de reglas civiles en derecho administrativo, especialmente en materia de prescripción de la acción de nulidad”, en Revista de Derecho, Universidad de Concepción, año 77, núms. 225-226, 2009, pp. 197-211.

Concha R., "El objeto ilícito contrario al derecho público, art. 1462 del Código Civil”, en Estudios de Derecho Civil V, LegalPublishing, Santiago, 2010, pp. 79-90.

Concha, R., Nulidad del contrato de la Administración. Aplicabilidad de las reglas civiles, Thomson Reuters, Santiago, 2012.

Delgado, J. “¿"Sanción de invalidez”? Los conceptos de invalidez y de sanción”, en id. "Las nulidades de los contratos: un sistema en evolución”, Editorial Aranzadi, Navarra, 2007, pp. 189-136.

Díez-Picazo, L., Fundamentos de Derecho civil patrimonial, Editorial Tecnos, Madrid, 1983.

Domínguez, R., Teoría general del negocio jurídico, Editorial Jurídica de Chile, Santiago, 2012.

Domínguez, R., "Todo el que tenga interés en ello... (sobre el art. 1683 del Código Civil chileno y el interés para alegar la nulidad absoluta)", en A.A.V.V. Estudios de Derecho Privado en homenaje al profesor Christian Larroumet, Ediciones Fundación Fernando Fueyo, Santiago, 2008, pp. 541-559.

FERnÁndez, T-R., La nulidad de los actos administrativos, Editorial Jurídica Venezolana, Caracas, 1979.

Ferrada, J.C., "Nuevas restricciones a la nulidad de derecho público como proceso administrativo: una jurisprudencia interesante, pero inconsistente", en Anuario de Derecho Público, Universidad Diego Portales, 2010, pp. 189-203.

Fiamma, G., "La acción constitucional de nulidad: un supremo aporte del constituyente de 1980 al Derecho Procesal Administrativo", en Revista de Derecho y Jurisprudencia, tomo 83, 1987, pp. 123-156.

Fiamma, G., "Acción constitucional de nulidad y legitimación activa objetiva”, en Revista de Derecho Público, núm. 49, 1991, pp. 91-98.

GuARinoni, R., "De lo que no hay. La inexistencia jurídica”, en Doxa, núm. 25, 2002, pp. 637-656. Hunneus, J., La constitución ante el Congreso, Imprenta de Los Tiempos Santiago, tomo II, 1879. JARA, J., La nulidad de derecho público ante la doctrina y la jurisprudencia, Editorial Libromar, Santiago, 2004.

LETELIER, R., "Un mal día no es eterno: Seis alcances en materia de invalidación y nulidad de los actos administrativos", en Revista de Derecho, Universidad de Concepción, núm. 212, 2002, pp. 691-728. 
Millar, J., La potestad invalidatoria en el derecho chileno s/e, tesis de doctorado, Universidad de Chile, 2008.

Nieto, A., "Estudio Preliminar", en Beladíez, M., Validez y Eficacia de los actos administrativos, Marcial Pons, Madrid, 1994, pp. 8-25.

O'TERo, M., La nulidad procesal civil, penal y de derecho público, Editorial Jurídica de Chile, Santiago, 2010.

PÉrez, J.L., "Validez, aplicabilidad y nulidad. Un análisis comparativo de la teoría del derecho y la dogmática jurídica", en Doxa, núm. 22, 1999, pp. 263-283.

Pierry, P., "La nulidad en Derecho Administrativo", en Revista de Derecho de la Universidad Católica de Valparaíso, núm. 15, 1994, pp. 79-100.

Reyes, J., "Reflexiones y bases acerca de la nulidad de Derecho público", en Revista de Derecho de la Universidad Católica de Valparaíso, núm. 17, 1997, pp. 383-421.

Santamaría, J., La nulidad de pleno derecho de los actos administrativos. Contribución a una teoría de la ineficacia en el derecho público, Instituto de Estudios Administrativos, Madrid, 1976.

Silva, E., Derecho Administrativo chileno y comparado. Actos, contratos y bienes, Editorial Jurídica de Chile, Santiago, 1995.

Soтo, E., "La nulidad de derecho público en el derecho chileno", en Revista de Derecho Público, núms. 47-48, 1990, pp. 11-25.

Sото, E., "La nulidad de derecho público referida a los actos de la administración", en Revista de Derecho de la Universidad Católica de Valparaíso, vol. 14,1992, pp. 417-431.

Sото, E., "La nulidad de derecho público: su actualidad", en Revista de derecho de la Universidad Católica de Valparaíso, vol. 18, 1997, pp. 347-355.

TAvolari, R., "La nulidad procesal en el derecho actual", en A.A.V.V. El proceso en acción, Editorial Libromar Santiago, 2000, pp. 243-278.

Thibierge, C., Nulidad, restituciones y responsabilidad (traducc. Gustavo de Greiff), Ed. Universidad Externado de Colombia, Bogotá, 2010. 